\title{
Battle lines drawn between 'nanobacteria' researchers
}

\section{Munich}

A Finnish scientist has formally asked the University of Kuopio to investigate the work of one of its senior researchers, who, he says, is making misleading but widely publicized claims to have discovered a new form of life, known as nanobacteria.

Over the past few years, a group of Finnish scientists have expressed concern that Olavi Kajander has failed to produce the necessary biochemical evidence to prove that the particles he claims to be nanobacteria are in fact alive. Kajander says that he has shown this, and he has supporters of his own, including some prominent researchers at the US space agency NASA.

Kajander's critics object to his contention that not only do nanobacteria exist, but that they could have important medical implications, and could represent a model for primitive life on Earth. They charge that Kajander's promotion of his theories is unethical, because it has encouraged other researchers to develop the work before the fundamental issue of the particles' biological nature has been clarified.

Kajander first identified small bacterium -like particles in biological fluids, under particular culture conditions, ten years ago. He describes them as spherical, with diameters of between 50 and 500 nanometres. They are heavily coated with hydroxyapatite, which Kajander says renders them highly resistant to chemicals and heat.

They could thus, he says, be the Earthbound equivalent of the fossilized structures observed in a meteorite assumed to have come from Mars, which some scientists regard as evidence of life there. Kajander says that their tough coats could have allowed the nanobacteria to survive the heat of entry into the Earth's atmosphere hidden within meteorites. He is now formally associated with NASA's Institute of Astrobiology, a virtual institute involving eleven research centres in the United States, collaborating with David McKay of the Johnson Space Center in Texas on Mars rock research.

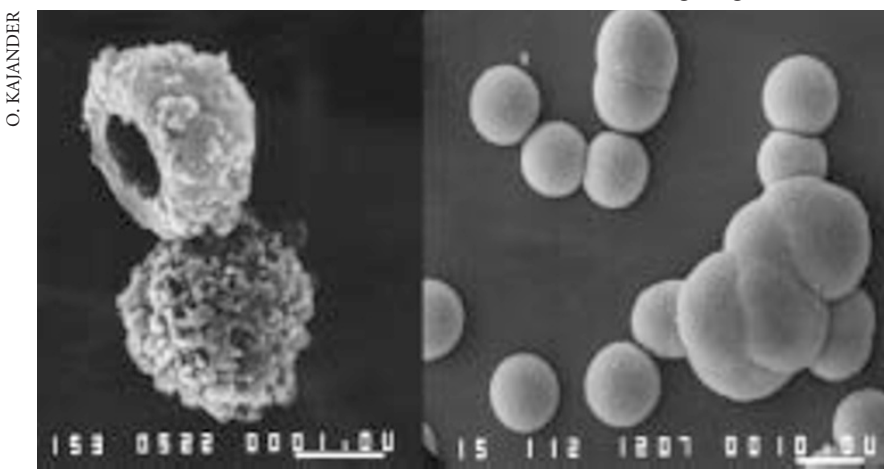

Kajander's evidence of biological material in his particles is dismissed by his critics as the result of possible contamination, or of faults in experimental design or interpretation. Kajander denies this, and claims that their exotic properties mean that standard biological tests are irrelevant to nanobacteria.

Critics counter that it is not necessary to invoke exotic properties for phenomena that could be more simply explained. They say that the apparent replication of the particles, for example, could be explained by crystallization from the culture medium.

Jouni Issakainen, a mycologist at Turku University Central Hospital, says that "wide epidemiological conclusions should not be drawn until the possible microbial nature of the particles is independently and critically assessed".

In a letter published last week in the Finnish science magazine Tiede 2000 (Science 2000), Issakainen alleges that Kajander selects electron micrographs and other morphological evidence to support his theory, and may even use technical tricks to generate structures that appear to resemble small bacteria. In a paper published last year in Proceedings of the National Academy of Sciences (PNAS 95, 8274-8279; 1998), Kajander claimed that he had identified DNA in nanobacteria. Issakainen says this cannot be substantiated because controls were not shown, and because Kajander increased the normal concentration of a DNA stain by an order of magnitude, as well as increasing the reaction time. Under these conditions, the stain can become nonspecific, says Issakainen.

Issakainen has written to the rector of the University of Kuopio requesting that the university investigate his suspicions that Kajander has "at least reported his observations carelessly, but possibly also had an intention to mislead".

Matti Saraste, a scientist at the European Molecular Biology Laboratory in Heidelberg, agrees that "caution should play a

Life as we know it? Kajander believes that structures like these 'castles' with thick mineral shells (left; scale bar, $1 \mu \mathrm{m})$ and the larger, shell-less blobs (right; scale bar, $10 \mu \mathrm{m}$ ) are living nanobacteria. major role until clear biochemical evidence that nanobacteria are living has been provided". Kajander has had years to prove his case, he says, "and the necessary tests are simple enough".

In a recently published article in the Finnish newspaper Helsingin Sanomat, he warns that Kajander's nanobacteria theory is developing into a "debate between two schools of thought, with proponents ... defining their opponents as unbelievers who are reluctant to accept new knowledge". A combination of "uncritical conduct of research, wishful thinking and a wish to gain publicity" could lead the public, and scientists themselves, to forget that the theory has - at least as yet - no basis, he warns.

The controversy intensified last year following publication of the PNAS paper, which implicated nanobacteria in the formation of kidney stones. The publication put Kajander's work firmly on the world stage.

Kajander complains his critics are simply prejudiced against the idea of nanobacteria. They do not argue scientifically, but "malevolently," he says, and without care for the potential medical benefits of his work. "In fact, I don't care whether nanobacteria have genetic material or not - we have shown that they are automatically replicating particles that produce apatite, and that they are involved in disease. And I want to cure disease."

Kajander has supporters who are building on his work. "We think that Kajander has proved the nanobacteria are living," says McKay. He intends to work with Kajander to develop nanobacterium biomarkers for testing Martian rock samples returned from future NASA missions.

Kajander's announcement that he has identified purported nanobacterial particles in 90 per cent of kidney stones has excited interest in several US research groups. Tom Hjelle, an associate professor of pharmacology at the University of Illinois, says that his group has morphological evidence that the nanobacteria he sees in polycystic kidneys can grow and divide. "There is serious interest out there among physicians and commercial companies in the idea of nanobacteria," he says. "And in the next year or so we will see a lot of reports being published."

Despite the controversy, the medical and scientific sections of the Academy of Finland have continued to support Kajander's work. Reviewers of a FM706,000 (US\$120,000) three-year grant application for work on nanobacteria "combining microbiology, geology and astrobiology" recommended rejection, but the grant was approved after the publication of the PNAS paper, and funded with money from the academy's 'risk fund'. "Although we recognize that there are no solid elements of a scientific basis, the academy decided to take a risk with the work," a spokesperson says. Alison Abbott 